\title{
Miscellany
}

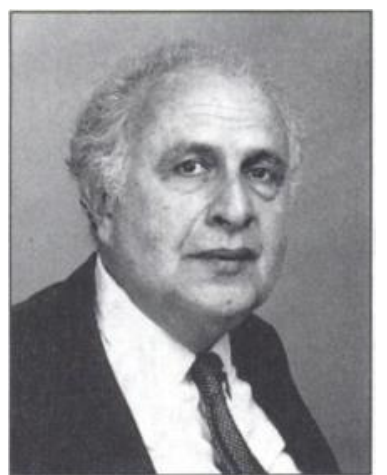

\section{Professor Michael Shepherd}

Professor Michael Shepherd has been nominated for election to Honorary Fellowship of the Royal Society of Medicine. Honorary Fellows are selected from among persons who have eminently distinguished themselves in the service of medicine and the branches of science allied to it. Professor Shepherd is one of only three psychiatrists currently so honoured.

\section{Psychiatric Advisers to the Centre for Mental Health Services Development}

The Centre for Mental Health Services Development (CMHSD) is the only universitybased research and consultancy organisation specialising in the development of community mental health services. Established by the Department of Health in 1991, it has now engaged in facilitating the development and implementation of mental health strategies in over 50 localities within the United Kingdom. Since the appointment of its new Director, Edward Peck, in April 1994, the CMHSD has ensured that each piece of work that it undertakes is informed by the contribution of a psychiatric adviser. The roles of the psychiatric advisers are to ensure that the agenda for the strategic review of services is informed by the issues which need to be addressed from a medical perspective and to ensure that the approach which emerges from the review is informed by best medical practice and deals adequately with the medical issues raised. Current psychiatric advisers include David Kingdon, Barry Matthews and Colin Godber. Roger Moss as senior psychiatric adviser coordinates the work of the psychiatric advisers and is a member of the CMHSD Senior Consultants Group which oversees the activities of the CMHSD. CMHSD now intends to increase the number of psychiatric advisers to inform the consultancy activity of the Centre. Consultant psychiatrists interested in becoming psychiatric advisers should contact Edward Peck, Director, Centre for Mental Health Services Development, King's College, London, Campden Hill Road, Kensington, London W8 7AH, for an information pack and/or contact Roger Moss (telephone/fax: 01392-495264 for an informal discussion). It is hoped that the new psychiatric advisers will be available to undertake projects in the autumn of 1995.

\section{UK Prix Galien Research Prize}

This prize, the first of its kind in this country, will be awarded annually to those individuals or teams from all walks of medicine and science, whose work has distinguished itself through innovation within the field of pharmaceutical research. The aim of the new award is to reward and encourage the efforts of research and development technicians who receive little acknowledgement outside their own scientific field. The new research prize joins the existing UK Prix Galien Award. Entry forms for both awards are available from the Secretariat, Quadrant House, The Quadrant, Sutton, Surrey SM2 5AS (telephone 0500-333-043). Closing date for entries: 15 September 1995.

\section{Good Practice in Community Mental Health Teams}

As part of a project to develop good practice among community mental health teams (CMHTs), the Mental Health Foundation charity is calling for people involved in setting up CMHTs, to provide information on how they 